\title{
Supracutaneous Locking Compression Plate for Grade I \& II Compound Fracture Distal Tibia-A Case Series
}

\author{
S. K. Venkatesh Gupta, Shyam Prasad Parimala \\ ${ }^{1}$ Department of Orthopaedics, Mamata Medical College, Khammam, India. \\ Email: drshyam09@gmail.com
}

Received May $2^{\text {nd }}, 2013$; revised May 30 ${ }^{\text {th }}, 2013$; accepted June $6^{\text {th }}, 2013$

Copyright (c) 2013 S. K. Venkatesh Gupta, Shyam Prasad Parimala. This is an open access article distributed under the Creative Commons Attribution License, which permits unrestricted use, distribution, and reproduction in any medium, provided the original work is properly cited.

\begin{abstract}
Background: Supracutaneous plating using a locking compression plate (LCP) as an external fixator in compound periarticular areas is facilitated by the development of anatomical plates. The soft tissue around the distal tibia is easily compromised by trauma and subsequent operative fracture treatment posing a definitive challenge in the distal tibia compound fractures. The purpose of this report is to describe our successful results using the metaphyseal locking compression plate (LCP) as an external fixator in the treatment of Grade I \& II compound fractures of distal tibia. Methodology: A total of five (05) patients underwent "supracutaneous plating" of the tibia using a metaphyseal locking compression plate. Average age was 36 years. Regular screw tract dressings were done. Average period of follow-up was 15 months. Results: The plate was in situ for an average of 24 weeks. There were no clinically significant screw site infections. In all five patients the plate was kept in place until there was complete consolidation both clinically and radiologically. At the latest follow-up (average 15 months), all patients were fully weight bearing with a fully healed tibia. All patients were infection-free with well-healed wounds. Conclusion: Routinely, after initial debridement and temporary bony stabilization is provided by external fixation in compound fractures of the distal tibia with significant soft tissue injury. Most external frames for the lower leg are bulky and cumbersome, causing significant problems for the patient. To circumvent these issues, we have successfully used an anatomically-contoured supracutaneous metaphyseal locking compression plate as external fixator in a series of five patients for grade I \& II compound fracture of the distal tibia.
\end{abstract}

Keywords: Locking Compression Plate; Compound Tibial Fractures; External Fixation of LCP

\section{Introduction}

The soft tissues around the ankle and distal tibia are easily compromised by trauma and subsequent fracture fixation posing a definitive challenge in healing of wounds post operatively [1,2]. Debridement followed by fracture fixation is the usually followed two stage treatment protocol in the management of grade I \& II compound fractures of distal tibia [3-6]. The instability of the fracture after debridement will compromise eradication of infection and wound healing [7-10]. Hence, temporary bony stabilization by external fixation is advocated [11]. Most of the external fixator frames used in lower tibial fixation are bulky and cumbersome to the patient, causing inconvenience to them in day to day activities and may also cause disturbance in gait while trying to clear from the opposite limb. Locking compression plate as an external fixation device has been described in the management of open fractures, non-union [12], septic arthritis [12] and even as an adjunct in distraction osteogenesis [13]. We report in this study, the outcome of anatomically-contoured locking compression plate as an external fixator device among five adult patients for grade I \& II compound fractures of distal tibia.

\section{Material and Methods}

During 2011-2013, a total of five patients underwent external plating ("supracutaneous plating" [14]) of the distal tibia using a metaphyseal locking plate. Two patients with grade I compound fractures and three of them with grade II compound fractures of distal tibia were included in the study. Average age of the patients was 36 years (range 28 - 42). Average time of presentation was 36 hours (range 10 hours to 3 days). In Table 1, the patient data are summarized. All patients in this cohort 
Table 1. Summary of patient data.

\begin{tabular}{|c|c|c|c|c|c|}
\hline Patient & $\begin{array}{c}\text { Age } \\
/ \\
\text { sex }\end{array}$ & Injury & $\begin{array}{l}\text { Duration of } \\
\text { LCP in } \\
\text { place }\end{array}$ & Outcome & $\begin{array}{l}\text { Follow-up } \\
\quad(\mathrm{mo})\end{array}$ \\
\hline 1 & 28/M & $\begin{array}{l}\text { Gr. I compound\# } \\
\text { distal third both } \\
\text { bones right leg }\end{array}$ & 20 weeks & Good & 18 \\
\hline 2 & $34 / \mathrm{M}$ & $\begin{array}{l}\text { Gr. II compound } \\
\text { pilon\# right leg }\end{array}$ & 22 weeks & Good & 18 \\
\hline 3 & $36 / \mathrm{M}$ & $\begin{array}{l}\text { Gr. I compound\# } \\
\text { distal third left } \\
\text { tibia\# }\end{array}$ & 24 weeks & Good & 12 \\
\hline 4 & $40 / \mathrm{M}$ & $\begin{array}{l}\text { Gr. II compound \# } \\
\text { both bones right leg }\end{array}$ & 26 weeks & Good & 18 \\
\hline 5 & $42 / \mathrm{M}$ & $\begin{array}{l}\text { Gr. II compound } \\
\text { pilon\# left leg }\end{array}$ & 28 weeks & Good & 18 \\
\hline
\end{tabular}

were followed up prospectively. Radiographs were obtained at regular intervals at 4 weeks, 8 weeks, 12 weeks, six months, one year and final follow up at one and a half year.

\section{Surgical Technique and Protocol [14]}

With the patient under spinal anaesthesia, the involved limb is prepared and draped in the usual standard sterile fashion. Pre-operative antibiotic treatment is given. No tourniquet is used; this is to allow intravenous antibiotics to reach the compound area.

A thorough debridement and wound wash is given. Fracture alignment is achieved prior to wound closure.
Compound wound is generally closed in one layer before the placement of the LCP, as the plate might limit easy access to wound.

Next, a LCP metaphyseal plate for the distal tibia of appropriate length is chosen. The plate is initially fixed to the proximal and distal fragments with a k-wire after certaining fracture reduction under fluoroscopy guidance. LCP is placed as close to the bone as possible, yet still allowing some space for swelling and regular wound care, to increase the mechanical stability of fixation. It is separated from the skin surface by a spacer of uniform thickness, like keeping a large needle holder. We prefer bi-cortical locked screw fixation when we use LCP as an external fixator. For the distal tibia, at least four screws $(4.5 \mathrm{~mm})$ proximally and three to four screws $(3.5 \mathrm{~mm})$ distally is recommended. Successive holes are drilled over locking drill-guides through stab incisions made over the intact soft tissue envelope and screws are placed first distally and later in proximal fragment after ensuing good reduction. (Figure 1) Screw tract and wound dressing is done.

Regular screw tract and compound wound dressings were done. Knee range of movement exercises and nonweight bearing walking was allowed from immediate post operative day. After 4 weeks, they were allowed toetouch partial weight bearing for next 6 weeks, and followed by partial weight bearing for 4 weeks. According to the stability of fixation and healing of fracture, they

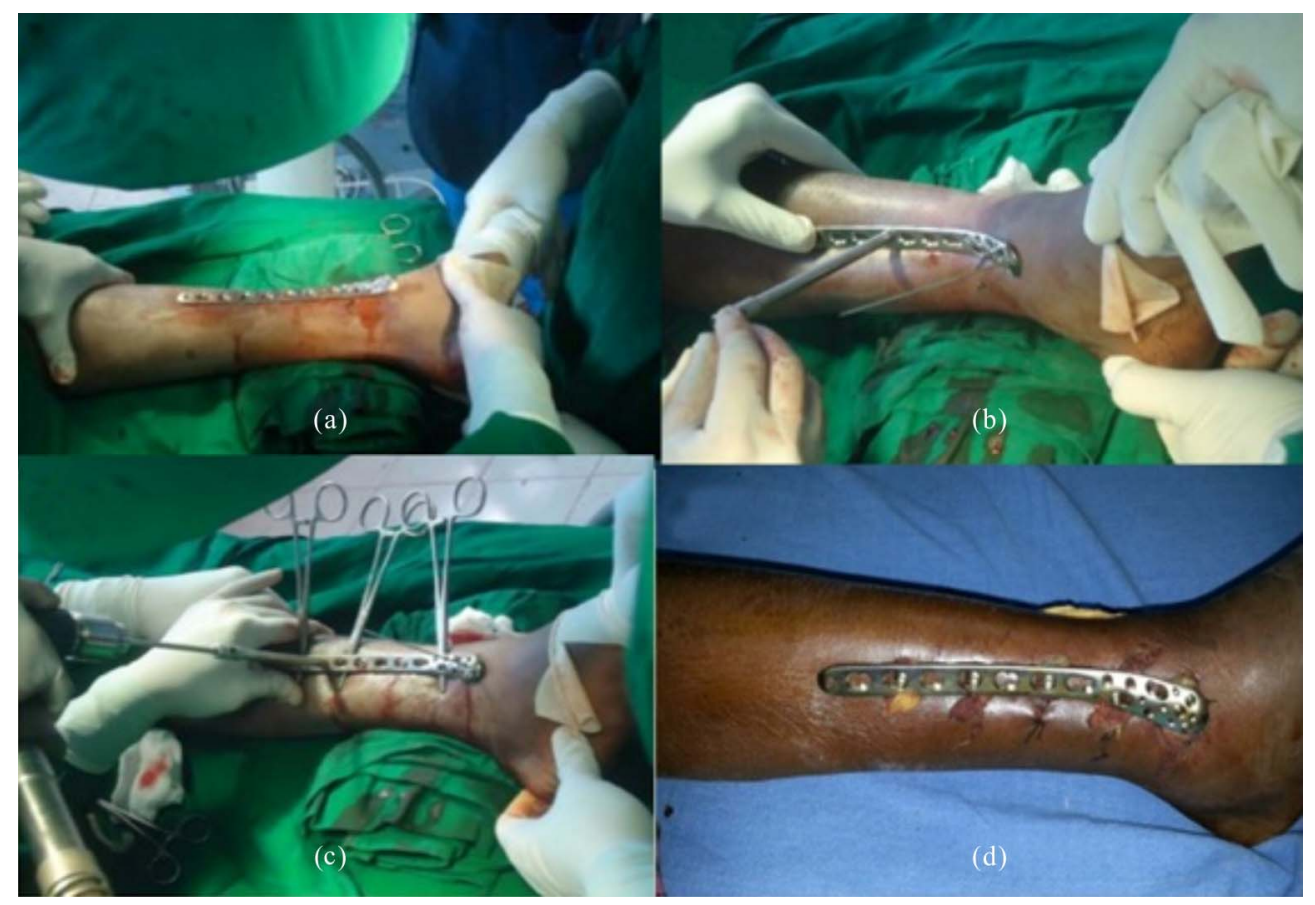

Figure 1. (a) Shows after anatomical reduction by giving traction and anatomically contoured plate is placed on distal tibia; (b) Shows plate is fixed to the bone by k-wires both proximally and distally; (c) Plate is fixed by locking screws by drilling with locking drill-guide; (d) Plate in-situ. 

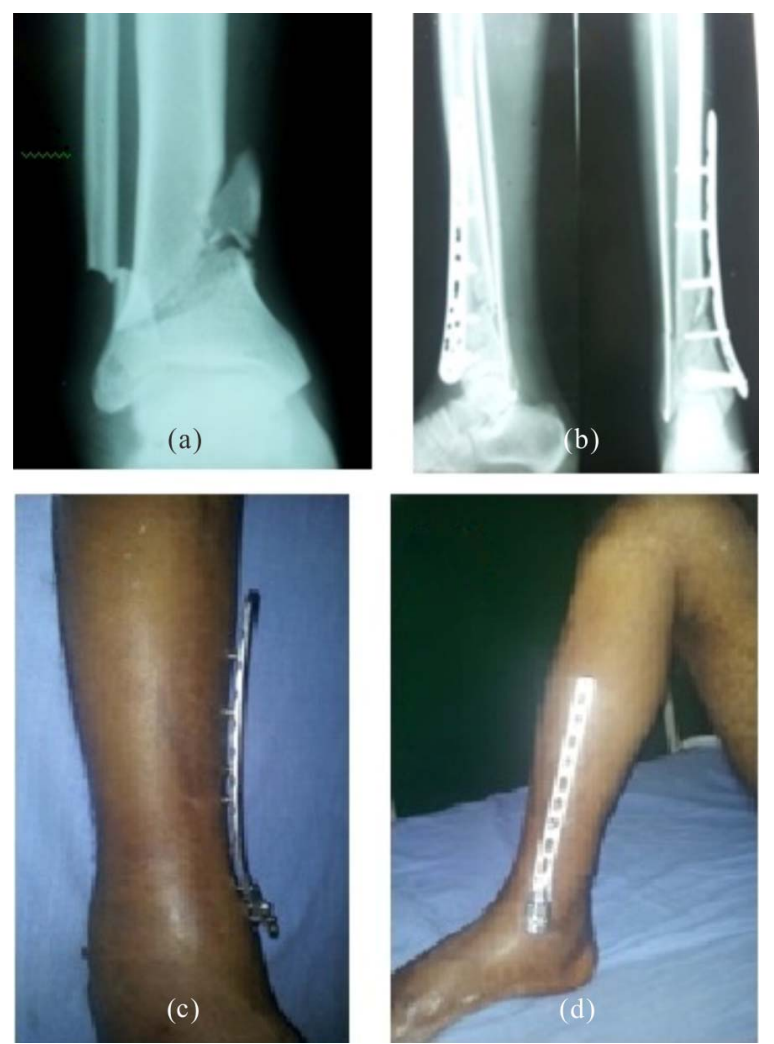

Figure 2. (a) Comminuted distal third fracture both bones leg pre-operative X-ray; (b) Post X-ray; (c) Clinical photograph with supracutaneous plate in-situ; (d) Bone-plate construct stability with knee flexion.

were started complete weight bearing.

\section{Results}

The plate was in situ for an average of 24 weeks (range 20 - 28). In all patients the plate was left in place until full bony healing both clinically and radiologically wasobtained. We did not see any significant screw tract infections or any loosening or failure of the hardware. The skin seems to tolerate the screws well and even seems to "adhere" to the screw. At the latest follow-up at an average of 15 months (range 8 - 22), all patients were fully weight bearing with a well-healed tibia. All patients were free of infection with well-healed wounds (Figures 2 and 3 ).

\section{Discussion}

The prevalence of distal tibia non-unions increases with the severity of open fractures. The endosteal and periosteal blood supply is often extensively destroyed when the open fracture occurs in the distal one-third of the tibia, which are regarded as the most important to the healing of a tibia fracture [12]. Using LCP as an external device not only stabilizes the fracture but also preserves the vascularity of distal tibia and promotes union. Non-union due to infection in compound fractures of distal tibia is a commonly encountered scenario which can be avoided by external stabilization devices [11].

However, LCP as an external device is superior and advantageous than other standard and circular external frames. LCP fixator can be concealed under clothing making it more acceptable to patients. There is much less tendency for the frame to strike the contra lateral lower leg in the swing-through phase of either leg during ambulation. Hardware removal can be performed under local anaesthesia. It imparts a less conspicuous radiographic silhouette compared with traditional fixators allowing ease of assessment of healing of fracture to treating surgeons. Small amounts of axial micro-motion may reduce stress shielding of fracture site. Load sharing during weight bearing may stimulate the developing callus until bony union. Controlled dynamisation by removing screws closest to the fracture site is possible, allowing some measure of control to the load sharing
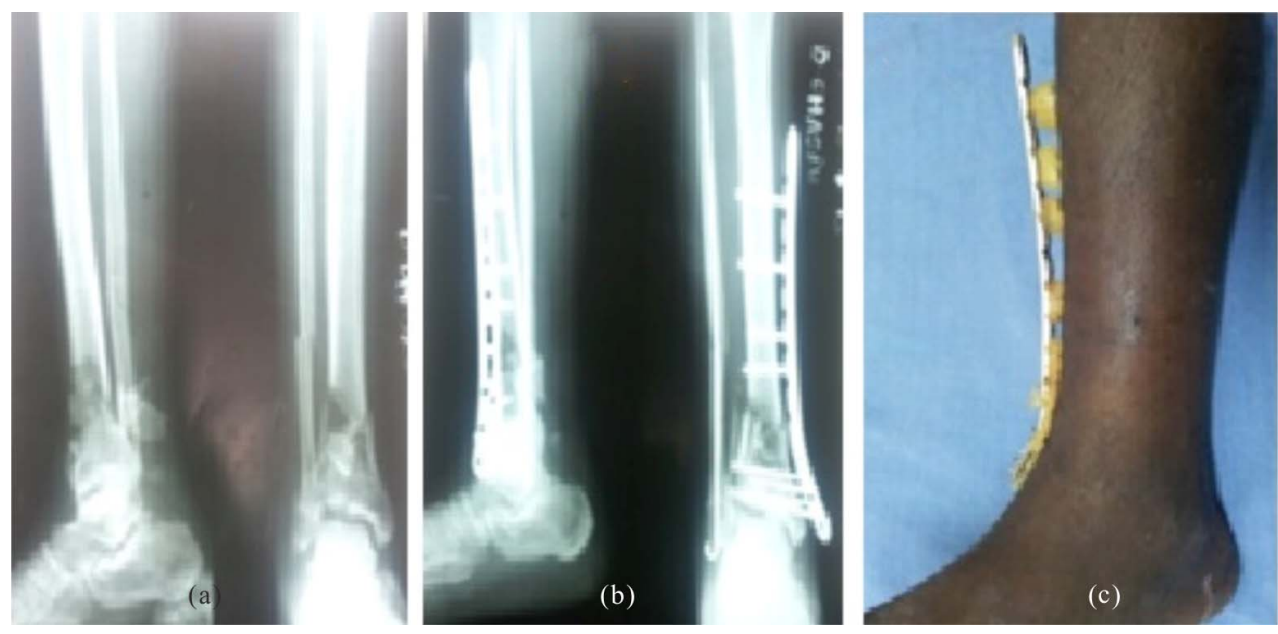

Figure 3. (a) Pre-operative X-ray; (b) Post-operative X-ray; (c) Clinical photograph. 
process. Multiple distal locking holes in the pre contoured plate provide more stability compared to the standard two large external fixator pins.

While the presented cases in our series were uncomplicated, a non-union rate of $5 \%-13 \%$ had been noted by other authors in this technique of fixation compared to $20 \%$ as in conventional external fixation [12]. During plate application, both plate and bone fragment can move independently, making accurate screw placement difficult as small shifts will make the plate translate to great deviations at the level of bone. Unlike the traditional fixation, mono-axial nature of locking head screw trajectory reduces the ability to compensate for imperfect placement, making it mandatory that anatomical reduction should be achieved prior to placement of first screw. While traditional constructs can be strengthened by stacking connecting rods, it is not possible for LCP external fixation. A Kloen's strategy of double LCP fixation should be employed in such cases requiring enhanced stability [15].

The consistent good outcome using this "supracutaneous technique" support our opinion of using Locking compression plate as external fixator in distal tibial fractures which are very well tolerated by patients and address the challenging problems of compound wound healing, non-union and osteomyelitis.

\section{REFERENCES}

[1] P. A. McCann, M. Jackson, S. T. Mitchell and R. M. Atkins, "Complications of Definitive Open Reduction and Internal Fixation of Pilon Fractures of the Distal Tibia," International Orthopaedics, Vol. 35, No. 3, 2011, pp. 413-418. doi:10.1007/s00264-010-1005-9

[2] T. W. Lau, F. Leung, C. F. Chan and S. P. Chow, "Wound Complication of Minimally Invasive Plate Osteosynthesis in Distal Tibia Fractures," International Orthopaedics, Vol. 32, No. 5, 2008, pp. 697-703. doi:10.1007/s00264-007-0384-z

[3] J. J. Hutson, "Salvage of Pilon Fracture Nonunion and Infection with Circular Tensioned Wire Fixation," Foot and Ankle Clinics, Vol. 13, No. 1, 2008, pp. 29-68. doi:10.1016/j.fcl.2007.11.004

[4] L. Eralp and M. Kocaoglu, "Distal Tibial Reconstruction with Use of a Circular External Fixator and an Intramedullary Nail: Surgical Technique,” The Journal of Bone \& Joint Surgery, Vol. 90, No. 2, 2008, pp. 181-194. doi:10.2106/JBJS.H.00467
[5] P. C. Cavadas and L. Landín, "Treatment of Recalcitrant Distal Tibial Nonunion Using the Descending Genicular Corticoperiosteal Free Flap,” Journal of Trauma, Vol. 64, No. 1, 2008, pp. 144-150. doi:10.1097/01.ta.0000249347.35050.3f

[6] M. E. Pannunzio, A. B. Chhabra, S. R. Golish, M. R. Brown and W. C. Pederson, "Free Fibula Transfer in the Treatment of Difficult Distal Tibia Fractures," Journal of Reconstructive Microsurgery, Vol. 23, No. 1, 2007, pp. 11-18. doi:10.1055/s-2006-958696

[7] D. Ring, J. B. Jupiter, B. S. Gan, R. Israeli and M. J. Yaremchuk, "Infected Nonunion of the Tibia," Clinical Orthopaedics and Related Research, Vol. 369, 1999, pp. 302-311. doi:10.1097/00003086-199912000-00032

[8] D. B. Thordarson, M. J. Patzakis, P. Holtom and R. Sherman, "Salvage of the Septic Ankle with Concomitant Tibial Osteomyelitis,” Foot \& Ankle International, Vol. 18, No. 3, 1997, pp. 151-156. doi:10.1177/107110079701800307

[9] C. L. Toh and J. B. Jupiter, "The Infected Nonunion of the Tibia,” Clinical Orthopaedics and Related Research, Vol. 315, 1995, pp. 176-191.

[10] S. A. F. Tulner, G. R. Schaap, S. D. Strackee, P. P. Besselaar, J. S. Luitse and R. K. Marti, “Long-Term Results of Multiple-Stage Treatment for Posttraumatic Osteomyelitis of the Tibia,” Journal of Trauma, Vol. 56, No. 3, 2004, pp. 633-642. doi:10.1097/01.TA.0000112327.50235.0A

[11] C. Collinge, J. Kennedy and A. Schmidt, "Temporary External Fixation of Lower Extremity,” Orthopedics-Healio, Vol. 33, No. 1, 2010, p. 4.

[12] G. M. M. J. Kerkhoffs, M. M. Kuipers, R. K. Marti and C. Werken, "External Fixation with Standard AO-Plates: Technique, Indications, and Results in 31 Cases," Journal of Orthopaedic Trauma, Vol. 17, No. 1, 2003, pp. 61-64. doi:10.1097/00005131-200301000-00010

[13] T. Appivatthakakul and K. Sanapanich, "The Locking Compression Plate as an External Fixator for Bone Transport in the Treatment of a Large Distal Tibial Defect: A Case Report,” Injury, Vol. 38, 2007, pp. 1318-1325.

[14] C. Y. L. Woon, M. K. Wong and T. S. Howe, "LCP External Fixation-External Application of an Internal Fixator: Two Cases and a Review of the Literature," Journal of Orthopaedic Surgery and Research, Vol. 5, No. 1, 2010, p. 19. doi:10.1186/1749-799X-5-19

[15] P. Kloen, "Supercutaneous Plating: Use of a Locking Compression Plate as an External Fixator," Journal of Orthopaedic Trauma, Vol. 23, No. 1, 2009, pp. 72-75. doi:10.1097/BOT.0b013e31818f8de4 